\title{
Influence of prednisone on serum level of tumor necrosis factor alpha, interferon gamma and interleukin-1 beta, in active pulmonary tuberculosis
}

\begin{abstract}
Introduction. Tumor necrosis factor alpha, interferon gamma and interleukin-1 beta modulate the interaction between T-cells and macrophages and play the key role in immune defense in Mycobacterium tuberculosis infection. Several studies have demonstrated that corticosteroids may improve clinical conditions of patients with active pulmonary tuberculosis.

Aim. The aim of the study was a potential impact of prednisone on the early immune response in HIV-negative young adults with active pulmonary tuberculosis, during the first four weeks of treatment.

Material and methods. The study included 38 adults, aged 18-39 years, with active pulmonary tuberculosis. The first group of patients received only anti-tuberculosis chemotherapy whereas the second group of patients was administered antituberculosis chemotherapy and $20 \mathrm{mg}$ prednisone, once daily. Serum levels of tumor necrosis factor-alpha, interferon-gamma and interleukin 1-beta were measured using ELISA kits before treatment initiation as well after two and four weeks of treatment, in both study groups.

Results. The highest serum levels of evaluated cytokines were observed before treatment initiation. Serum levels of cytokines were significantly decreased in patients who received anti-tuberculosis drugs and prednisone, compare to those not treated with prednisone $(\mathrm{p}<0.001)$, in all study periods.

Conclusions. Adjunctive therapy, like $20 \mathrm{mg}$ prednisone daily, remarkably inhibited the secretion of inflammatory cytokines during the early stage of active pulmonary tuberculosis in HIV-negative young adults, which is likely to be beneficial for this group of patients.
\end{abstract}

Keywords: pulmonary tuberculosis, TNF-alpha, IFN-gamma, IL-1 beta, immune defense mechanism, prednisone.

DOI: $10.2478 /$ pjph-2014-0009

\section{INTRODUCTION}

The interaction between $\mathrm{T}$ cells and macrophages is essential immune defense mechanisms in Mycobacterium tuberculosis (MTB) infection, resulting in the release production and release of pro-inflammatory cytokines such as tumor necrosis factor alpha (TNF-alpha) interferon gamma (IFN-gamma) and interleukin 1-beta (IL-1 beta) by these cells [1-3]. Cellular immune responses triggered by these inflammatory cytokines activate typical immune defense mechanisms against MTB inflammation [4-6]. TNF-alpha and IL-1 beta exert well documented effects on the vascular endothelium, promoting endothelial damage and endarteritis. This vascular occlusion has been identified as an important factor leading to ischemia, lung tissue necrosis and lung damage $[7,8]$ Several controlled trials have shown that clinical conditions and radiographic changes of patients with pulmonary $\mathrm{TB}$, treated with anti-TB chemotherapy and small doses of corticosteroids improve more rapidly than of those who did not receive corticosteroids [9-14].

\begin{abstract}
AIM
The aim of our study was to determine the impact of small doses of prednisone on early immune responses represented by serum TNF-alpha, IFN-gamma and IL-1 beta levels, in the early stage of adequately treated, active pulmonary tuberculosis in HIV-negative young adults.
\end{abstract}

\section{MATERIAL AND METHODS}

Fifty-eight consecutive patients: 32 males (aged 18-33, the mean age 25 years) and 26 females (aged 25-34 years, mean age 28 years) with active pulmonary tuberculosis were enrolled into the study. Patients with a severe form of disease and acute respiratory failure were excluded from the study, as they required more than $20 \mathrm{mg}$ of steroids per day and additional concomitant medications. None of the included patients suffered from concomitant diseases or received corticosteroids during the last year. In all patients, the ELISA HIV test was negative. In all study patients, acid-fast tubercle bacilli were identified in sputum culture.

\footnotetext{
${ }^{1}$ Department of Pulmonology, Oncology and Allergology of Medical University, Lublin, Poland

${ }^{2}$ Department of Dermatology, Venerology and Paediatric Dermatology of Medical University, Lublin, Poland

${ }^{3}$ Trainee doctor, extern; Independent NHS Clinical Hospital No. 4, Lublin, Poland
} 
The study design was approved by the local Ethics Committee of Medical University of Lublin. In our randomized, doubleblind, placebo-controlled study, patients received anti-TB drugs (Rifampicin: $10 \mathrm{mg} / \mathrm{kg} / 24 \mathrm{~h}$ Isoniazid: $5 \mathrm{mg} / \mathrm{kg} / 24 \mathrm{~h}$, Pyrazinamid $15 \mathrm{mg} / \mathrm{kg} / 24 \mathrm{~h}$ ) and placebo or oral prednisone in a daily dose of $20 \mathrm{mg}$. The patients were divided into two groups: group I $(\mathrm{n}=29)$, prednisone non-recipients and group II $(\mathrm{n}=27)$ prednisone-recipients. The control group consisted of 17 healthy volunteers. All patients and controls gave their informed consent to participate in the study. The study was conducted over the period of four weeks. Serum samples were collected from the study groups and controls, immediately the initiation of treatment and after two and four weeks of treatment. Serum levels of IFN gamma were determined by the ELISA kit (Genzyme Diagnostics, GBL) with the minimum detection limit of $5 \mathrm{pg} / \mathrm{ml}$ and curve range between zero and $500 \mathrm{pg} / \mathrm{mL}$. Serum concentrations of TNF-alpha were determined using the ELISA kit (Genzyme Diagnostics, GBL) with a standard curve range of zero to $500 \mathrm{pg} / \mathrm{ml}$ and lower limit of sensitivity at $10 \mathrm{pg} / \mathrm{ml}$. Serum levels of IL-beta were measured by the ELISA kit (Genzyme Diagnostics, GBL) with the lower limit of sensitivity of the assay $20 \mathrm{pg} / \mathrm{ml}$. All serum samples were randomly assigned code numbers and assayed in a single batch in a double-blind manner. The data obtained were expressed as the mean values with standard deviation. Statistical differences between control and study groups as well as between prednisone non-recipients (group I) and prednisone recipients (group II) were assessed using the Student's t-test with the fiducially limit $\mathrm{p}=0.05$. Serial changes in IFN-gamma, TNF-alpha and IL-1 beta levels were examined by analysis of variance and any significance was further sought by the least significance difference.

\section{RESULTS}

The mean values of serum level of IFN gamma of the study patients and control group in all study periods are shown in Figure 1.

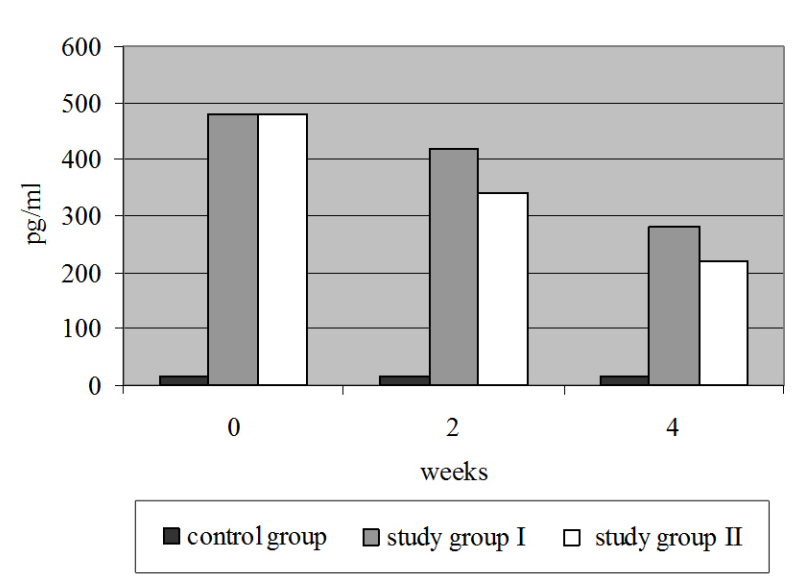

FIGURE 1. Serum level of IFN gamma in the tuberculosis patients: group I (prednisone non-recipients) and group II (prednisone recipients) and control group (healthy volunteers) during four-weeks study period.

The mean serum IFN-gamma level before treatment initiation (week 0) in study patients was markedly raised: $480 \mathrm{pg} / \mathrm{ml}(\mathrm{SD} \pm 24)$ compared to $15 \mathrm{pg} / \mathrm{ml},(\mathrm{SD} \pm 4)$ in controls. The statistically significant differences $(\mathrm{p}<0.05)$ were observed in both study groups between week 0 and week
4 and between prednisone recipients (group II) $340 \mathrm{pg} / \mathrm{ml}$ ( $\mathrm{SD} \pm 20$ ) and prednisone non-recipients (group I): $420 \mathrm{pg} / \mathrm{ml}$, $(\mathrm{SD} \pm 18)$ after two weeks of treatment. After four weeks of treatment the mean serum level of IFN gamma in group II was $220 \mathrm{pg} / \mathrm{ml}(\mathrm{SD} \pm 18)$ in group I and $282 \mathrm{pg} / \mathrm{ml}(\mathrm{SD} \pm 16)$ in group II; the difference was not significant. These values were significantly higher than in healthy subjects $(p<0.01)$ throughout study period.

The mean serum IL-1 beta level in study and control groups in all study periods are shown in Figure 2.

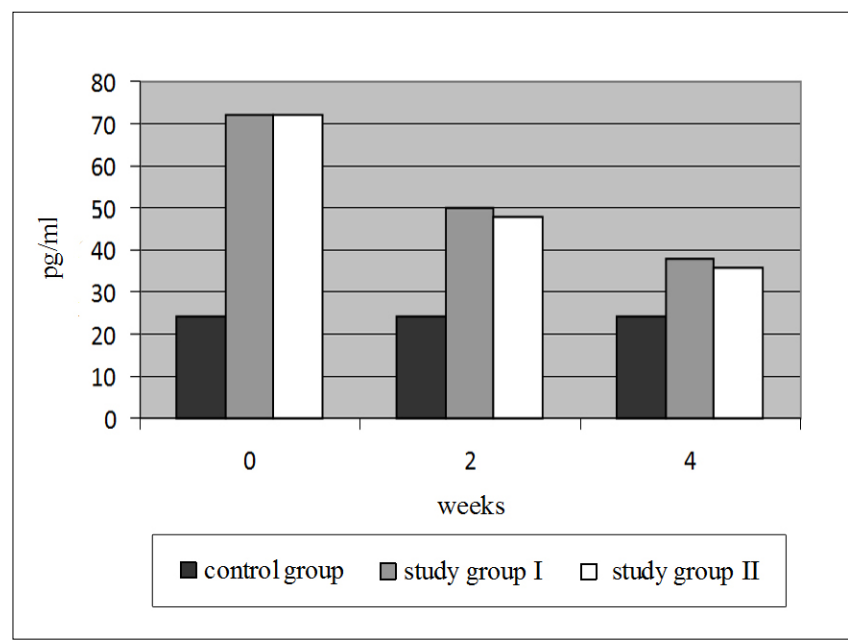

FIGURE 2. Serum level of interleukin 1-beta in tuberculosis patients: group I (prednisone non-recipients) and group II (prednisone recipients) and control group (healthy volunteers) during four-weeks study period.

During the 4-weeks study we observed a significant gradual decline in serum IL-1 beta levels in patients receiving both anti-TB chemotherapy and prednisone i.e. before treatment initiation: $72 \mathrm{pg} / \mathrm{ml}(\mathrm{SD} \pm 8)$, after two weeks of treatment: $43 \mathrm{pg} / \mathrm{ml}(\mathrm{SD} \pm 12)$, and after four weeks of treatment: $35 \mathrm{pg} / \mathrm{ml}(\mathrm{SD} \pm 12)(\mathrm{p}<0.005)$. In patients receiving only antiTB chemotherapy a gradual decrease in mean values of IL-1 beta was noted, compared to week 0, i.e.: $50 \mathrm{pg} / \mathrm{ml}(\mathrm{SD} \pm 12)$ after two weeks of treatment, and $38 \mathrm{pg} / \mathrm{ml}(\mathrm{SD} \pm 8)$ after four weeks of treatment. They were significantly higher than in the control group: $24 \mathrm{pg} / \mathrm{ml}(\mathrm{SD} \pm 6)$ but not significantly different from those in prednisone recipients.

The mean serum TNF-alpha levels in study patients and control groups are shown in Figure 3.

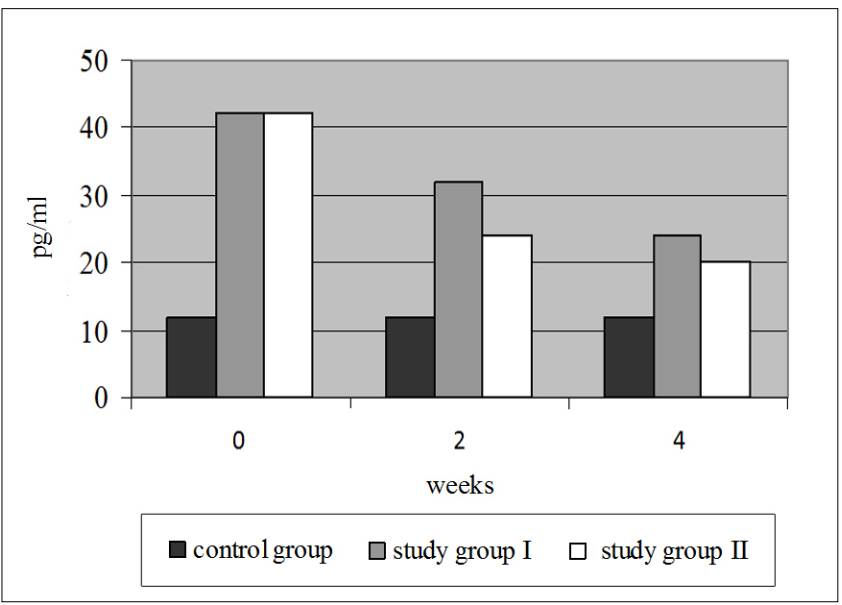

FIGURE 2. Serum level of TNF-alpha in tuberculosis patients: group I (prednisone non-recipients) and group II (prednisone recipients) and control group (healthy volunteers) during the four-weeks study period. 
The mean serum TNF-alpha level in study patients before initiating treatment was $42 \mathrm{pg} / \mathrm{ml}(\mathrm{SD} \pm 10)$. After two weeks of treatment, markedly reduced TNF alpha levels were observed in TB-patients receiving anti-TB chemotherapy and prednisone (group II) with we observed with: the mean value of $24 \mathrm{pg} / \mathrm{ml}(\mathrm{SD} \pm 6)$ which was statistically significantly different compared to week $0(\mathrm{p}<0.01)$ and non-recipients prednisone (group I) $(\mathrm{p}<0.05)$.in the same period of observation. In patients receiving only anti-TB chemotherapy (group I), significant decline in TNF-alpha serum levels was found after two weeks of treatment, with the mean value of $32 \mathrm{pg} / \mathrm{ml}(\mathrm{SD} \pm 8)$ compared week $0(\mathrm{p}<0.05)$. After four weeks of observation the mean values of TNF-alpha in prednisone recipients and non-recipients were not statistically different compared to each other and week 2. Moreover, they were significantly higher than those observed in the control group: $12 \mathrm{pg} / \mathrm{ml}(\mathrm{SD} \pm 4),(\mathrm{p}<0.05)$ in all study periods.

\section{DISCUSSION}

The first randomized, controlled trial to examine the effect of adjunctive corticosteroid therapy in TB-patients treated with proper anti-TB chemotherapy was conducted in Scotland [9]. In 1959, Weinstein and Koler [14] in their randomized, double-blind study demonstrated that radiographic abnormalities in patients with active pulmonary tuberculosis cleared significantly faster in corticosteroids recipients than in non-recipients. The US Public Health Service Tuberculosis Therapy multi-center study, published in 1960, evidenced beneficial or detrimental effects of the low dosage of prednisone $(20 \mathrm{mg} /$ day at initiation $)$ in patients with active pulmonary tuberculosis [10]. Several further investigations analyzed acute responses within the first days up to two weeks, long-term responses: fibrosis or cavitations and the of conversion rate of sputum smears from positive to negative. Many of them demonstrated that corticosteroids, as adjunctive therapy in TB patients treated with anti-TB chemotherapy, were associated with a faster clinical response and with the prompt cessation of clinical and radiological symptoms [11-13]. The beneficial effects of low doses of corticosteroids in TB infection may be mediated through the modulation of T-cell function $[13,14]$. Corticosteroids are the strongest inhibitors of pro-inflammatory cytokines, including TNF-alpha, IFN-gamma and IL-1 beta $[12,16]$. It is known, that TNF-alpha has some harmful effects such as acute phase inflammatory events, including fever, weight loss and tissue necrosis. TNF-alpha plays also a protective role against mycobacterial infection and is responsible for the formation and maintenance of granulomas. Decreased TNF-alpha secretion in active pulmonary tuberculosis may lead to extra-pulmonary tuberculosis or disseminated disease [5,17-19].

In our study, we observed remarkable decrease in serum TNF-alpha levels in patients receiving anti-TB chemotherapy and $20 \mathrm{mg}$ prednisone daily, during the first two weeks of treatment. The decrease was higher than that observed in study patients who received only anti-TB chemotherapy, and this tendency was maintained over the next two weeks.

IFN-gamma produced by all classes of lymphocytes and potentially by alveolar macrophages, up-regulates production of TNF-alpha $[1,5,8]$. In our study, we observed gradual decline of IFN-gamma serum levels during the first four weeks of treatment, especially in prednisone recipients. On the other hand, decreased secretion of IFN-gamma may affect low TNF-alpha levels, due to prednisone-dependent suppression of cell immunity in TB patients, which was confirmed by decreased levels of IL-1 beta, particularly in those patients who received prednisone as adjunctive therapy.

Our study findings revealed that small doses of corticosteroids, administered as adjunctive therapy with anti-TB treatment, in HIV-negative young adults, caused significantly greater reduction in serum level of pro-inflammatory cytokines such as TNF-alpha, IFN gamma and IL-1 beta. This impact was visible during the first four weeks of treatment, i.e. in a very early stage of the disease. Significantly lower serum levels of pro-inflammatory cytokines in prednisonerecipients influence depression of inflammatory response in TB infection.

Some clinicians have used prednisone to manage pulmonary tuberculosis. It has been evidenced that small doses of prednisone are helpful in decreasing the need for hospitalization of TB patients. Prednisone has also led to more-rapid improvement of clinical symptoms, radiographic findings and the patient's quality of live [20]. But until now, the practice has not been investigated in the sufficient number of randomized controlled trials.

\section{REFERENCES}

1. Toosi Z. The inflammatory response in Mycobacterium tuberculosis infection. Arch Immunol Ther Exper. 2000;48:515-9.

2. Algood HMS, Lin PL, Yankura D, et al. TNF influences chemokine expression of macrophages in vitro and that of CD $11 \mathrm{~b}+$ cells in vivo during Mycobacterium tuberculosis infection. J Immunol. 2004;172:684657.

3. Dinarello CA. Proinflammatory cytokines. Chest. 2000;118:503-8.

4. Kelley J. State of the art cytokines of the lung. Am Rev Resp Dis. 1990;141:765-88.

5. Zganiacz A, Santosuasso M, Wang J, et al. TNF-alpha is a critical negative regulator of type 1 immune activation during intracellular bacterial infection. J Clin Invest. 2004;113:401-13.

6. Tsao TCY, Hong J-H, Li L-F, et al. Imbalances between its soluble receptor forms and interleukin-1 beta and interleukin-1-receptor antagonist in pulmonary tuberculosis. Chest. 2000;117:103-9.

7. Scanga CA, Mohan VP, Yu K, et al. T-cells cause reactivation tuberculosis despite continued expression of interferon gamma and nitric oxide synthase. J Exp Med. 2000;192:347-58.

8. Research Committee of the Tuberculosis Society of Scotland. Prednisolone in the treatment of pulmonary tuberculosis: a controlled trial. Br Med J. 1957;2:1131-4.

9. United States Public Health Service. Tuberculosis Therapy Trials; Preliminary observations from a controlled trial of prednisolone in the treatment of pulmonary tuberculosis. Am Rev Resp Dis. 1960;81;598-600.

10. Research Committee of the British Tuberculosis Association. Trial of corticotrophin and prednisone with chemotherapy in pulmonary tuberculosis: a two year radiographic follow-up. Tubercle. 1963;44:484-7.

11. Muthuswamy P, Hu YC, Carasso B, et al. Prednisone as adjunctive therapy in the management of pulmonary tuberculosis, report of 12 cases and review of the literature. Chest. 1995;107:1616-30.

12. Senderovitz T, Viscun K. Corticosteroids and tuberculosis. Res Med. 1994;88:565-9.

13. Weinstein HJ, Koler JJ. Adrenocorticosteroids in the treatment of tuberculosis. N Eng J Med. 1959;260:412-7.

14. Chan HS, Pang JA. Effects of corticosteroids on deteriotation of endobronchial tuberculosis during chemotherapy. Chest. 1989;96:1195-6. 
15. World Medical Association Declaration of Helsinki. Ethical Principles for Medical Research Involving Human Subjects. 59 WMA General Assembly, Seoul, October 2008.

16. Tsao TC, Hong J, Huang C, et al. Increased TNF-alpha, IL-1 beta and Il-6 levels in the bronchoalveolar lavage fluid with the upregulation of their mRNA in macrophages lavaged from patients with active pulmonary tuberculosis. Tuber Lung Dis. 1999;79:279-85.

17. Barreto Pereira C, Palaci M, Leite OHM, et al. Monocyte cytokine secretion in patients with pulmonary tuberculosis differs from that of healthy infected subjects and correlates with clinical manifestations. Microb Infect. 2004;1:25-33.

18. Golden MP, Vikram HR. Extrapulmonary tuberculosis: An overview. Am Fam Physic. 2005;72:1761-8.

19. Chang JS, Huggett JF, Dheda K, et al. Mycobacterium tuberculosis induces selective upregulation of TLRs in the mononuclear leukocyte of patients with active pulmonary tuberculosis. J Immunol. 2006;176:3010-8.

20. Meintjes G, Wilkinson RJ, Morroni C, et al. Randomized placebo-controlled trial of prednisone for paradoxical tuberculosis-associated immune reconstruction inflammatory syndrome. AIDS. 2010;15:2381-90.

\section{Corresponding author}

Barbara Rybacka-Chabros

Department of Pulmonology, Allergology and Oncology,

Medical University of Lublin

8 Jaczewskiego Str., 20-950 Lublin, Poland

tel : +48 81 742-44-31, +48 510-973-716

E-mail: doctor_86@o2.pl 